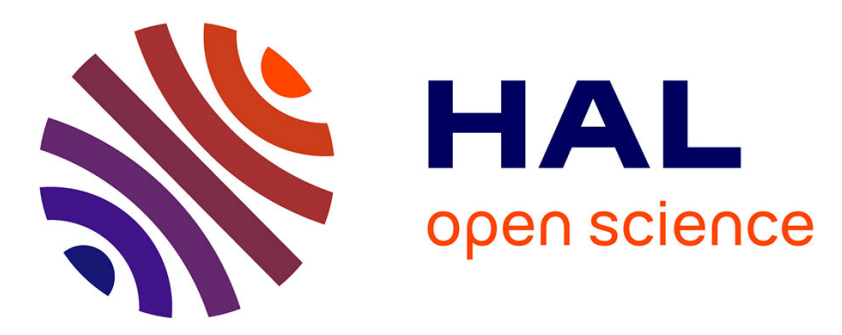

\title{
Structural control on earthquake behaviors revealed by high-resolution Vp/Vs imaging along the Gofar transform fault, East Pacific Rise
}

\author{
H. Guo, H. Zhang, B. Froment
}

\section{- To cite this version:}

H. Guo, H. Zhang, B. Froment. Structural control on earthquake behaviors revealed by high-resolution $\mathrm{Vp} / \mathrm{Vs}$ imaging along the Gofar transform fault, East Pacific Rise. Earth and Planetary Science Letters, 2018, 499, pp.243-255. 10.1016/j.epsl.2018.07.037 . hal-02881784

\author{
HAL Id: hal-02881784 \\ https://hal.science/hal-02881784
}

Submitted on 16 Jul 2020

HAL is a multi-disciplinary open access archive for the deposit and dissemination of scientific research documents, whether they are published or not. The documents may come from teaching and research institutions in France or abroad, or from public or private research centers.
L'archive ouverte pluridisciplinaire HAL, est destinée au dépôt et à la diffusion de documents scientifiques de niveau recherche, publiés ou non, émanant des établissements d'enseignement et de recherche français ou étrangers, des laboratoires publics ou privés. 
1 Structural control on earthquake behaviors revealed by high-resolution

$2 \mathrm{Vp} / \mathrm{Vs}$ imaging along the Gofar transform fault, East Pacific Rise

3

$4 \quad$ Hao Guo $^{1}$, Haijiang Zhang ${ }^{1}$, Berenice Froment ${ }^{2}$

5

6 'Laboratory of Seismology and Physics of Earth's Interior, School of Earth and Space

7 Sciences, University of Science and Technology of China, Hefei, Anhui, China.

$8 \quad$ Institut de Radioprotection et de Sûreté Nucléaire, Fontenay-aux-Roses, France.

9

10

11

12

Submitted to Earth and Planetary Science Letters

13

14

February, 2018

15

16 


\section{Abstract}

Gofar transform fault (TF), East Pacific Rise can generate $M_{w}$ 5.5-6 large earthquakes quasiperiodically on some specific segments, which are separated by stationary rupture barriers. Small earthquakes along the strike have clear spatial and temporal evolution. To better understand the cause of various behaviors of large and small earthquakes on this oceanic TF, we have determined high-resolution earthquake locations within a period of one year covering the $2008 \mathrm{M}_{\mathrm{w}} 6.0$ earthquake as well as $\mathrm{Vp}$, Vs and Vp/Vs models along the Gofar TF using a well recorded ocean bottom seismograph dataset and a new consistency constrained double-difference tomography method. S-wave arrival times are significantly improved compared to catalog times by an automatic arrival picking procedure. High-precision waveform cross-correlation differential times are also used. The tomographic $\mathrm{Vp} / \mathrm{Vs}$ model reveals strong structural variations at multiple scales along the fault strike, which likely control the generation of large earthquakes in a specific segment, the propagation of mainshock ruptures and the spatial distribution of small earthquakes along the Gofar TF. (1)

Key words: Transform fault; Temporal and spatial earthquake evolution; Fault segmentation; Double-Difference tomography; Vp/Vs inversion

\section{Highlights:}

1. Extended DD tomography method for more reliable determination of $\mathrm{Vp} / \mathrm{Vs}$

2. Segmentations in earthquake locations and velocity models along the Gofar transform fault

3. Strong structural variations control the behavior of large and small earthquakes 


\section{Introduction}

Fault can slip in different modes, including slow slip, non-volcanic tremor, steady creep, microseismicity and large dangerous earthquake (Ide et al., 2007; Peng and Gomberg, 2010), but our understanding of their physical mechanisms is still very limited (Harris, 2016). In contrast to continental faults, mid-ocean ridge transform faults (RTFs) provide a better tectonic environment for studying how fault zone physical properties influence fault slip and earthquake behaviors because they have relatively simple geometries with average slip rates that are well defined by plate spreading velocities, and show in general more homogeneous compositions and better predictable thermal structures (Roland et al., 2012).

In this study, we focus on the short $(\sim 90 \mathrm{~km})$ and high-slip-rate $(\sim 14 \mathrm{~cm} / \mathrm{yr})$ Gofar transform fault (TF) on the equatorial East Pacific Rise (EPR). Gofar TF can generate large $\left(M_{\mathrm{w}} \sim 6\right)$ earthquakes quasiperiodically every 5 to 6 years on some specific patches, which are separated by some stationary rupture barriers that can stop the propagation of large earthquakes (Fig. 1) (McGuire, 2008; McGuire et al., 2012).

In 2008, motivated by the observed regular EPR seismic cycles (McGuire, 2008), Woods Hole Oceanographic Institution (WHOI) deployed a broadband ocean bottom seismograph (OBS) array including 16 stations around the Gofar TF for 1-year continuous monitoring, which successfully captured a $\mathrm{M}_{\mathrm{w}} 6.0$ earthquake on the westernmost segment of the fault on 18 September 2008 (Fig. 1) and provided an unprecedented dataset (McGuire et al., 2012). In addition to this year-long OBS array, a wide-angle seismic refraction survey line was also conducted across a rupture barrier segment (Fig. 1) (Roland et al., 2012).

Using the 2008 year-long OBS array dataset, McGuire et al. (2012) detected and located tens of thousands of earthquakes, including background seismicity before the occurrence of foreshocks for the $2008 \mathrm{M}_{\mathrm{w}} 6.0$ earthquake, a week-long sequence of foreshocks, the M6 main shock and its aftershocks (Fig. 1a), as well as an earthquake swarm that occurred in December. Along-strike spatial and temporal evolution of the year-long seismicity showed strong variations in earthquake rupture properties both in 
space and time, which will be further shown in this paper with higher resolution. McGuire et al. (2012) suggested that a $\sim 10-\mathrm{km}$ rupture barrier segment associated with abundant foreshocks and deep seismicity (i.e. segment 1 defined later in this paper) between the $2008 \mathrm{M}_{\mathrm{w}} 6.0$ and $2007 \mathrm{M}_{\mathrm{w}} 6.2$ mainshock rupture areas (two colored ellipses in Fig. 1) could stop the main shock rupture, probably as a result of enhanced fluid circulation.

Using the active-source seismic dataset, Roland et al. (2012) determined a tomographic P-wave velocity ( $\mathrm{Vp}$ ) model across the fault. This wide-angle reflection survey line just passed through the rupture barrier segment (Fig. 1). A low-velocity fault zone with Vp reduced by $\sim 10-20 \%$ throughout the crust was imaged. Based on the analysis of local gravity data from Pickle et al. (2009), this low-velocity fault zone was interpreted to be highly damaged with enhanced fluid-filled porosity rather than to be caused by serpentinization (Roland et al., 2012).

Combining both datasets, Froment et al. (2014) determined the Vp model along the strike of the Gofar TF using the DD tomography method (Zhang and Thurber, 2003). They found relatively higher $\mathrm{Vp}$ in the segment where $2008 \mathrm{M}_{\mathrm{w}} 6.0$ main shock occurred (i.e. segment 2 defined later in this paper) than its adjacent segments in seismogenic depths and suggested that the mainshock segment was composed of relatively intact rock while rocks of its adjacent segments were damaged.

In Froment et al. (2014), however, only the Vp model was inverted and the Vs model was not determined because of poor quality of the S-wave arrival time picks (see Section 2.1 and the left panel in Fig. 2). It is known that $\mathrm{Vs}$ and $\mathrm{Vp} / \mathrm{Vs}$, especially the latter, are more sensitive than $\mathrm{Vp}$ to the existence of fractures and fluids (Kuster and Toksöz, 1974; Takei, 2002). Therefore, in this study, we aim to determine high-resolution earthquake locations and $\mathrm{Vp}$, Vs and $\mathrm{Vp} / \mathrm{Vs}$ models along the fault strike to better resolve the relation between structure variations and various earthquake behaviors along the Gofar TF.

\section{Dataset and method}




\subsection{Dataset}

103 For the earthquake catalog covering the calendar year of 2008 (McGuire et al., 104 2012), the original P- and S-wave first-arrival catalog dataset was built using the 105 standard short-term average to long-term average ratio (STA/LTA) algorithm. In this 106 study, we select earthquakes with at least 14 arrivals from the original catalog. The 107 quality of the S-wave first arrival times is greatly improved by using an 108 Akaike-Information-criteria (AIC)-based algorithm following the steps listed below:

109 (1) Same as McGuire et al. (2012), the raw waveform (sampling frequency of 50 or $110100 \mathrm{~Hz}$ ) is processed by first removing its mean and then bandpass filtered 111 between $5 \sim 12 \mathrm{~Hz}$;

112 (2) A time window of $1.6 \mathrm{~s}$ is selected around the original $\mathrm{S}$ arrival time;

113 (3) The AIC method (Maeda, 1985; Zhang et al. 2003) is applied to the selected time 114 windows of two horizontal components, resulting in two new S picks;

115 (4) Both S picks from step 3 would be rejected in any of the three cases: the 116 signal-to-noise ratios (SNR) of both horizontal components around the new picks 117 are lower than a threshold which is visually determined; new picks are too close to 118 the boundaries of the selected time window; the difference between two new picks $119(d t)$ is larger than a threshold which is set to be $0.2 \mathrm{~s}$.

120 (5) Finally, we select the new pick from the component that has higher SNR and use $121 d t$ to define the associated picking uncertainty.

To demonstrate the improvement in the quality of new $S$ arrival picks, we randomly select some nearby earthquakes recorded on a common station and then 125 align their waveforms with respect to their arrival picks. Due to the similar ray paths 126 from these nearby earthquakes to the common station, these waveforms are expected 127 to be highly similar around their first arrivals. After aligning these waveforms 128 according to the original and new first arrivals (left and middle panels in Fig. 2), it is 129 clear that the waveforms around new picks are much better aligned, indicating that the 130 quality of S-wave arrival picks has been significantly improved compared to the 
131 original ones. The comparison of travel time curves based on original and newly

132 picked $\mathrm{S}$ arrivals further confirms the quality improvement in new picks (Fig. S1).

133 The root-mean-square (RMS) value of absolute differences between new and original

$134 \mathrm{~S}$ arrival times is $0.195 \mathrm{~s}$, which can be used to quantify the improvement resulting

135 from our new picking procedure.

136 In addition to the passive earthquake data, P-wave first arrival times from active 137 sources crossing the Gofar TF are also included. Overall, our final dataset includes a 138 total of 7432 earthquakes and 271 active shots recorded by 21 OBS stations (Fig. 1), 139 associated with 39,710 P-wave, 25,385 S-wave and 24,950 S-P arrival times. From 140 absolute $\mathrm{P}$ and $\mathrm{S}$ arrival times, we construct 269,737 P-wave, 166,779 S-wave, and $141 \quad 163,517$ S-P differential arrival times for pairs of events on common stations.

142 In addition to the catalog arrival times, we also measure $\mathrm{P}$ - and S-wave 143 differential times with the WCC technique [Du et al., 2004] which makes use of the 144 waveform similarity for pairs of nearby events recorded on common stations due to 145 similar ray paths. The waveform alignment is further improved by using WCC data 146 compared to arrival picks (Fig. 2), indicating the WCC data is more accurate. In total, 147 we obtained 1,562,783 P-wave and 1,335,490 S-wave WCC differential arrival times, 148 respectively, from which 928,431 S-P WCC differential times are obtained.

\subsection{Extended DD tomography method for $\mathrm{Vp} / \mathrm{Vs}$ inversion}

The $\mathrm{P}$ - or S-wave arrival time residual $r_{k}^{i}$ between the observed $\left(T_{k}^{i}\right)^{\text {obs }}$ and

152 calculated arrival times $\left(T_{k}^{i}\right)^{\text {cal }}$ from event $i$ to station $k$, can be linearly related to 153 the perturbations of earthquake location in the three directions $\left(d x_{1}, d x_{2}, d x_{3}\right)$, origin 154 time $(d \tau)$, and slowness $(\delta \mathrm{u})$ along ray path elements $(d s)$, as follows,

$$
r_{k}^{i}=\left(T_{k}^{i}\right)^{o b s}-\left(T_{k}^{i}\right)^{c a l}=\sum_{m=1}^{3} \frac{\partial T_{k}^{i}}{\partial x_{m}^{i}} d x_{m}^{i}+d \tau^{i}+\int_{i}^{k} \delta u d s
$$

Following Thurber (1993), by assuming identical P- and S-wave ray paths, the

157 S-P arrival time residual $r_{k s p}^{i}$ between the observed $\left(T_{k s p}^{i}\right)^{o b s}$ and calculated S-P 158 arrival times $\left(T_{k s p}^{i}\right)^{\text {cal }}$ from event $i$ to station $k$ can be linearly related to the 
159

160

161

162

164

166

168

perturbations of earthquake location and the ratio of $\mathrm{Vp}$ to $\mathrm{Vs}\left(\delta\left(V_{p} / V_{s}\right)\right)$ along the ray path, as follows,

$$
r_{k s p}^{i}=\left(T_{k s p}^{i}\right)^{o b s}-\left(T_{k s p}^{i}\right)^{c a l}=\sum_{m=1}^{3}\left(\frac{\partial T_{k s}^{i}}{\partial x_{m}^{i}}-\frac{\partial T_{k p}^{i}}{\partial x_{m}^{i}}\right) d x_{m}^{i}+\int_{i}^{k} \frac{\delta\left(V_{p} / V_{s}\right)}{V_{p}} d s
$$

The event origin time term can be cancelled out by using S-P times. It is also noted that, the clock errors on the waveform arrival times which are due to the difficulty of clock synchronization on OBS (Gouédard et al., 2014) can be removed by using S-P times because the clock errors of $\mathrm{P}$ - and $\mathrm{S}$-wave arrival times for common earthquakes on common stations are nearly the same.

By subtracting a similar equation for a nearby event $j$ recorded on the station $k$ from equation (1), we obtain the so-called double difference (i.e. the residual between the observed and calculated event-pair differential times) $d r_{k}^{i j}$ to solve for the perturbations of earthquake locations and slowness models, as follows,

$$
\begin{aligned}
& d r_{k}^{i j}=\left(T_{k}^{i}-T_{k}^{j}\right)^{o b s}-\left(T_{k}^{i}-T_{k}^{j}\right)^{c a l} \\
& \quad=\sum_{m=1}^{3} \frac{\partial T_{k}^{i}}{\partial x_{m}^{i}} d x_{m}^{i}+d \tau^{i}-\sum_{m=1}^{3} \frac{\partial T_{k}^{j}}{\partial x_{m}^{j}} d x_{m}^{j}-d \tau^{j} \\
& +\int_{i}^{k} \delta u d s-\int_{j}^{k} \delta u d s
\end{aligned}
$$

Similarly, by subtracting a similar equation for a nearby event $j$ recorded on station $k$ from equation (2), we obtain the residual between the observed and calculated event-pair differential S-P times $d r_{k s p}^{i j}$ to solve the perturbations of earthquake locations and $v_{p} / v_{s}$, as follows,

$$
\begin{aligned}
& d r_{k s p}^{i j}=\left(T_{k s p}^{i}-T_{k s p}^{j}\right)^{o b s}-\left(T_{k s p}^{i}-T_{k s p}^{j}\right)^{c a l} \\
&= \sum_{m=1}^{3}\left(\frac{\partial T_{k s}^{i}}{\partial x_{m}^{i}}-\frac{\partial T_{k p}^{i}}{\partial x_{m}^{i}}\right) d x_{m}^{i}-\sum_{m=1}^{3}\left(\frac{\partial T_{k s}^{j}}{\partial x_{m}^{j}}-\frac{\partial T_{k p}^{j}}{\partial x_{m}^{j}}\right) d x_{m}^{j} \\
&+\int_{i}^{k} \frac{\delta\left(V_{p} / V_{s}\right)}{V_{p}} d s-\int_{j}^{k} \frac{\delta\left(V_{p} / V_{s}\right)}{V_{p}} d s
\end{aligned}
$$

The inversion system of the original DD tomography algorithm (tomoDD, Zhang and Thurber, 2003) includes equation (1) and (3) to make use of absolute arrival times 
and event-pair differential arrival times to jointly invert earthquake locations as well as Vp and Vs models. Equations (2) and (4) were further included into the DD inversion system by Zhang et al. (2009) to make use of absolute and differential P, S and S-P times to determine earthquake locations as well as Vp, Vs and Vp/Vs models simultaneously.

Due to similar ray paths outside the source region for pairs of nearby events recorded on common stations, the sensitivities of differential S-P times (i.e. equation 4) on $\mathrm{Vp} / \mathrm{Vs}$ model anomalies outside the source region will be largely reduced and thus the model near the source region can be better resolved. Moreover, high-precision WCC event-pair differential times can be used to further improve earthquake locations and velocity models.

For $\mathrm{Vp} / \mathrm{Vs}$ inversion, the assumption of similar ray paths for $\mathrm{P}$ and $\mathrm{S}$ waves is critical. To solve this potential problem, $\mathrm{P}$ - and $\mathrm{S}$-wave ray paths will be checked at each iteration to remove some S-P times from the inversion if the associated ray paths differ by more than a specified threshold (Zhang et al., 2009).

Actually, we can get two Vp/Vs models after the inversion. One is derived from the direct division of the separate Vp and Vs model. The second one is inverted from S-P times (i.e. Equations 2 and 4). The first one has larger uncertainty than the separate Vp and Vs models because the Vs model is generally more poorly resolved than the $\mathrm{Vp}$ model due to larger S-wave data error and fewer S-wave data. In comparison, the second one is more reliable but has lower resolution because the requirement of similar P- and S-wave ray paths would remove some S-P data. For these two $\mathrm{Vp} / \mathrm{Vs}$ models, they are generally not consistent both in shape and amplitude. To have a consistent $\mathrm{Vp} / \mathrm{Vs}$ model with both high resolution and high reliability, here we propose a consistency constraint to the two $\mathrm{Vp} / \mathrm{Vs}$ models, as follows,

$$
\Delta=k_{1}-k_{2}=\frac{u_{s}}{u_{p}}-k_{2}
$$

where $k_{1}=\frac{u_{s}}{u_{p}}=\frac{V_{p}}{V_{s}}$ represents the one from the direct division of Vp by Vs, with $u_{p}$ and $u_{s}$ represent the $\mathrm{P}$ - and $\mathrm{S}$-wave slowness models, respectively. $k_{2}$ represents 
the directly inverted $\mathrm{Vp} / \mathrm{Vs}$ model by using S-P times. $\Delta$ is the difference between

$210 k_{1}$ and $k_{2}$. The misfit (denoted as $d \Delta$ ) between the true $\Delta$ that is zero and the 211 predicted one, can be linearly related to the perturbations of $u_{p}, u_{s}$ and $k_{2}$ (i.e. $212 d u_{p}, d u_{s}$ and $d k_{2}$ ) by using a truncated Taylor series expansion,

$$
\begin{gathered}
\mathrm{d} \Delta=\Delta^{\text {true }}-\Delta^{c a l}=k_{2}-\frac{u_{s}}{u_{p}} \\
=\frac{\partial \Delta}{\partial u_{p}} d u_{p}+\frac{\partial \Delta}{\partial u_{s}} d u_{s}+\frac{\partial \Delta}{\partial k_{2}} d k_{2} \\
=-\frac{u_{s}}{u_{p}{ }^{2}} d u_{p}+\frac{1}{u_{p}} d u_{s}-d k_{2}
\end{gathered}
$$

By minimizing the misfit $d \Delta$, we can determine a reliable $\mathrm{Vp} / \mathrm{Vs}$ model that has similar resolution to that of individual Vp and Vs models, which will be shown with a checkerboard resolution test in the next section. And the structure of the inverted $\mathrm{Vp}$, $\mathrm{Vs}$ and $\mathrm{Vp} / \mathrm{Vs}$ models can also be more consistent compared to the original method of Zhang et al. (2009) without such a constraint.

\section{Inversion details and the analysis of location uncertainty and}

\section{model resolution}

For inversion, we use the same Cartesian coordinate system as Froment et al. (2014), which is centered at station G08 and the Y axis is rotated $12^{\circ}$ clockwise so that the $\mathrm{X}$ axis is parallel to the fault strike (Fig. 1b). The grid nodes used for inversion are positioned at $X=-40,-35,-30,-28,-26,-24,-22,-20,-18,-16,-15,-14$, $-13,-12,-11,-10,-9,-8,-7,-6,-5,-4,-3,-2-1,0,1,2,3,4,5,6.5,9.5,13.5,18,25$, $43 \mathrm{~km}, \mathrm{Y}=-16.5-8,-5,-2,0,1,2,3,4,6,9,12,15 \mathrm{~km}$, and $\mathrm{Z}=0,2,2.96,3.5,4,5,6$, $7,8,9,10,13,25 \mathrm{~km}$, respectively.

Fig. 3c shows the initial 1-D Vp model which is constructed by averaging the $v_{p}$ 230 model of the low-velocity fault zone determined by the 2-D across-fault active-source 231 reflection study (Roland et al., 2012), and the Vp models $10 \mathrm{~km}$ north and south of the 232 active fault trace (Roland et al., 2012) which are used as the representative of the 233 normal velocity model of the EPR crust. The initial $\mathrm{Vp} / \mathrm{Vs}$ value is 1.73 , and the 
234 initial Vs model is converted from the initial Vp and Vp/Vs. We adjust the initial 235 model to fit the topographic variations of the local seafloor bathymetry (Fig. 3c).

236 We perform the inversion with a hierarchical weighting scheme for the catalog 237 and WCC data (Zhang and Thurber, 2003). Regularization parameters, including 238 smoothing and damping factors, which are used to stabilize the inversion, are selected 239 with a trade-off analysis (Figs. 4a and 4b). Along with the inversion iterations, it can 240 be seen that data residuals for both of the catalog and WCC data converge well (Fig. $2414 c)$.

242 To estimate the model resolution, we perform two synthetic tests including a 243 checkerboard test and a restoration test (Zhao and Hasegawa, 1993), both of which 244 have been widely used in seismic tomography. For the checkerboard test, we create a 245 checkerboard velocity model by adding positive and negative 5\% velocity anomalies 246 to the initial 1-D model at alternating grid nodes. Checkerboard patterns for Vp and 247 Vs models are set to be opposite at the same grid node so that the checkerboard model 248 of $\mathrm{Vp} / \mathrm{Vs}$ can alternate with positive $10.5 \%$ and negative $-9.5 \%$ anomalies. Then the 249 checkerboard models and earthquake relocations are used to generate synthetic 250 absolute and differential times that have the same distribution as the real data. The 251 synthetic data are then used for inversion starting from the same 1-D model as the real 252 data inversion. Fig. 5 shows the along-strike cross sections of the recovered 253 checkerboard models, which indicate that the fault-zone structures at depths of 6 to 10 $254 \mathrm{~km}$ below the mean sea level are well resolved. Moreover, the comparison between 255 the inversions with and without the $\mathrm{Vp} / \mathrm{Vs}$ consistency constraint apparently shows 256 that the new algorithm can improve the resolution of Vp/Vs model (Figs. 5c-d).

257 For the restoration model resolution test with noisy synthetic data (Figs. S4 and 258 S5), the key features in the recovered velocity models from the real data inversion that 259 will be discussed in next section are reliable (see Supplementary Materials for 260 details).

261 We also check the fitting of the active-source data (see Supplementary Materials 262 for details), which further indicates that our velocity model is reliable (Fig. S6).

263 To estimate the uncertainties of final event relocations, we adopt a bootstrapping 
resampling method, the same as Guo and Zhang (2017) (see supplementary materials for details). The median values of the relative location uncertainties estimated from

266 bootstrapping analysis are $0.040,0.041$, and $0.078 \mathrm{~km}$ in the $\mathrm{X}, \mathrm{Y}$ and $\mathrm{Z}$ directions, 267 respectively, which could be slightly underestimated due to the effect of regularization applied to inversion (Guo and Zhang, 2017).

\section{Results}

We separate the fault into 4 segments (Fig. 5a) according to different features in velocity anomalies and earthquake activity. Segments 1 to 3 are defined based on the along-strike segmentation of the Vp model determined by Froment et al. (2014) in that the segments 1 and 3 show low $\mathrm{Vp}$ while the segment 2 where the main shock occurred, shows high Vp. Compared to Froment et al. (2014), we add a westernmost segment 4 to represent the region where an earthquake swarm occurred in December 2008.

In the following sections on results and discussions, it is noted that the depth values mentioned through the paper are referred to be relative to the sea level unless otherwise is specified.

\subsection{Earthquake relocations}

Figs. 6a-b show the map view and along-strike cross section of earthquake relocations with small location uncertainties which are estimated with bootstrapping analysis. Fig. S2 shows all relocations. Compared to the initial catalog locations (Figs.

287 DD relocations by Froment et al. (2014) with only P-wave arrival data, our DD relocations from the joint inversion of earthquake locations and velocity models with

289 P- and S-wave arrival data and WCC data are more concentrated in both horizontal 290 and vertical views, suggesting that the relative locations have been greatly improved. 291 Absolute locations are also well resolved due to the utilization of absolute arrival 292 times and the joint inversion. Improved earthquake locations outline a very clear 
delineation of the active fault trace at about $\mathrm{Y}=2 \mathrm{~km}$, with the seismicity in the western segment gradually deflecting to the south (Fig. 6a).

The earthquakes after the mainshock (black dots in Fig. 6b) have a tendency to be systematically deeper than the pre-mainshock background seismicity (gray dots in Fig. 6b). Froment et al. (2014) observed a significant velocity reduction below G08 in segment $1(-2 \%$ to $-6 \%)$ during the foreshock period and after the main shock, as well as below G06 in segment $2(-4 \%$ to $-10 \%)$ after the main shock. This means that the velocity model inverted using all the data is an average of the possible temporal velocity changes for the period and should generally be smaller than the actual velocity model in segments 1 and 2 before foreshocks. Therefore, background earthquakes would be shifted $\sim 0.5 \mathrm{~km}$ shallower, and the foreshocks and earthquakes after the mainshock would be $\sim 0.5 \mathrm{~km}$ deeper, which is consistent with the relocation results shown in Fig. 6b. Froment et al. (2014) did not observe a velocity reduction in segment 3 due to the data gap before the main shock, but based on the systematic depth differences between background seismicity and the earthquakes after the main shock (Fig. 6b) it could indicate a velocity reduction also in segment 3 after the main shock.

Overall, the seismogenic depth in the crust along the strike is in the depth of $\sim 6-8$ $\mathrm{km}$ below the sea level (i.e. $\sim 3-5 \mathrm{~km}$ below the sea floor) (Figs. 6b-c). However, it is clear that there exist a lot of relatively deep earthquakes in the depth range of $\sim 5-8 \mathrm{~km}$ below the sea floor in segments 1,3 and 4 (Fig. 6c) compared to segment 2. In comparison, McGuire et al. (2012) determined much deeper seismicity ( 7-11 km below sea floor) in segment 1, which could explain some observed large S-P times (see Fig. 3 in McGuire et al., 2012) assuming a constant Vp/Vs of 1.73. Our relocations from the joint inversion indicates that the large S-P times should be attributed to both the deeper extent of the seismicity and the high $\mathrm{Vp} / \mathrm{Vs}$ structure in segment 1 (see section 4.3), rather than much deeper extent of the seismicity alone. 
McGuire et al. (2012) has shown the temporal and spatial (along-strike) evolution of the year-long seismicity using the complete event catalog. By using 324 higher-resolution relocations, we can more clearly show the evolution patterns for the seismicity at the crustal seismogenic depths from $Z=6$ to $8 \mathrm{~km}$ (Fig. 7). It is worth noting that, although the earthquakes used in this study are partially selected from the catalog used by McGuire et al. (2012), the evolution pattern should still be representative because the selection criteria is not related to the earthquake location and occurrence time.

From 1 January to 9 September (day 253), the Gofar TF from $X=-30$ to $30 \mathrm{~km}$ experienced a lot of background seismicity. Among all the segments, segment 1 actually experienced the highest rate of background seismicity, as already shown in 333 McGuire et al. (2012). Then, segment 1 culminated in a spectacular swarm of 334 foreshocks within one week from 10 September (day 254) to 17 September (day 261), 335 which was immediately terminated on 18 September (day 262) when the $2008 \mathrm{M}_{\mathrm{w}} 6.0$ 336 main shock occurred in the nearby segment 2 . For this reason, segment 1 is also called 337 the foreshock zone. After the main shock, segments 2 and 3 experienced high-rate 338 seismicity for a few weeks and then gradually recovered to the level of the 339 background seismicity. After the main shock, the seismicity in segment 1 ceased to a 340 very low level in the depth of $Z=6$ to $8 \mathrm{~km}$ (Figs. 6b and 7) but was relatively active 341 in the deep area although it is also much weaker than the pre-main shock level (Fig. 342 6b). For this reason, segment 1 is seen as a rupture barrier segment. On 10-17 343 December, the westernmost segment 4 experienced another swarm, which can be 344 better viewed from the more complete catalog of McGuire et al. (2012).

345 It is clear that the earthquakes preferentially occur in specified segments along 346 the fault in specific periods, as delineated by a series of rectangles in Fig. 7, while the 347 zones between these segments have no or very weak seismicity. Highly segmented 348 seismicity along the fault, even within the three large segments 1-3, suggests very 349 strong structural variation along the fault. 


\subsection{Velocity models}

In this section, we describe the along-strike velocity models at $\mathrm{Y}=2 \mathrm{~km}$ (Fig. 8). Because segment 4 is very close to the tomographic inversion boundary, we only focus here on segments 1,2 and 3.

Fig. 8 shows the along-strike cross sections of $\mathrm{Vp}$, Vs and $\mathrm{Vp} / \mathrm{Vs}$ models. In addition, we also showed $\mathrm{Vp}$ and $\mathrm{Vs}$ differences with respect to the reference 1-D Vp and Vs models. The reference Vp model (Fig. S3) is derived from averaging two 1-D velocity profiles located $10 \mathrm{~km}$ south and north of the Gofar TF (Roland et al., 2012), which can be seen as the normal EPR crustal Vp model around the Gofar fault zone. The reference Vs model is derived by assuming a constant $\mathrm{Vp} / \mathrm{Vs}$ of 1.8 , which is a mean EPR crustal Vp/Vs estimated from an ambient noise study (Yao et al., 2011). We also approximately estimate the Moho depth with the Vp contour of $7.6 \mathrm{~km} / \mathrm{s}$ (Detrick et al., 1993), but from another inversion with denser grid intervals in depth and coarser grid interval in the $\mathrm{Y}$ direction. This parameterization allows for a higher resolution in depth and thus can be used to better estimate the Moho discontinuity

\subsubsection{Segment 1}

Segment 1 has thinner crustal thickness than an average 6km-thick oceanic crust (Fig. 8f) and shows a strong structural segmentation. Three Vp/Vs anomaly zones (A, B, C) can be identified from high-resolution velocity models (Fig. 8). Compared to

372 the reference crustal model, zone $\mathrm{A}(\mathrm{X}=-7$ to $3 \mathrm{~km}, \mathrm{Z}=5$ to $7.5 \mathrm{~km})$ shows low $\mathrm{Vp}$ ( - -5\% to $-15 \%)$, low Vs $(\sim-10 \%$ to $-20 \%)$ and high $\mathrm{Vp} / \mathrm{Vs}(\sim 1.9)$; zone $\mathrm{B}(\mathrm{X}=-3$ to 0

$374 \mathrm{~km}, \mathrm{Z}=6$ to $9 \mathrm{~km})$ shows low Vp ( - $5 \%$ to $-13 \%)$, low Vs ( 0\% to $-10 \%)$ and a relatively low $\mathrm{Vp} / \mathrm{Vs}(<1.75)$; zone $\mathrm{C}(\mathrm{X}=0$ to $4 \mathrm{~km}, \mathrm{Z}=5$ to $8 \mathrm{~km})$ shows low $\mathrm{Vp}(\sim$ $0 \%$ to $-10 \%)$, low Vs ( -10\% to $-20 \%)$, high $\mathrm{Vp} / \mathrm{Vs}(>2.0)$.

\subsubsection{Segment 2}


Segment 2 shows normal crustal thickness (i.e. $\sim 6 \mathrm{~km}$ ), which is $\sim 1 \mathrm{~km}$ larger 380 than its adjacent segments 1 and 3 (Fig. 8f). This is consistent with lower velocity 381 values in the deeper part of segment $2(Z>7.5 \mathrm{~km})$ than its eastern and western zones. 382 In the shallow part $(\mathrm{Z}<7.5 \mathrm{~km})$, however, $\mathrm{Vp}$ and $\mathrm{Vs}$ are actually higher than the 383 neighboring segments at the same depth. The $\mathrm{Vp} / \mathrm{Vs}$ model in segment 2 from shallow 384 to deep zones is normal or slightly high ( 1.8) but much lower than neighboring 385 segments.

\subsubsection{Segment 3}

In segment 3 , there are two $\mathrm{Vp} / \mathrm{Vs}$ anomalous zones $\mathrm{D}$ and $\mathrm{E}$ from $\mathrm{Z}=5$ to 7.5 $\mathrm{km}$, associated with low $\mathrm{Vp}(\sim 0$ to $-10 \%)$, low Vs ( -10\% to $-20 \%)$ and high $\mathrm{Vp} / \mathrm{Vs}$ (>1.9). Although these two zones are connected in the shallow depth, but they are separate in seismogenic depth (Fig. 8c). The crust in segment 3 is thinner than the average 6-km crustal thickness.

It is noted that the 1-D reference model which is used to represent the normal, undamaged model, is not very suitable for the calculation of velocity difference models in segments 1 and 3 and is likely underestimated in these two segments, as evidenced by their shallower Moho depths revealed by the inversion (Fig. 8f) compared to the normal depth of $\mathrm{Vp}=7.6 \mathrm{~km} / \mathrm{s}$ in the 1-D reference model (Fig. S3).

398 Thus the velocity differences in segments 1 and 3 shown in Fig. 7d-e are overestimated and should be smaller, which means that the amplitude of the velocity

400 decrease of zones A-E should be larger and that the low-velocity structure will be 401 more clear at the bottom boundaries of zones B and E.

\section{Interpretations and Discussions}

404 In this section, we will interpret the velocity structures in segments 1-3 and 405 discuss the relationship between structural variations and earthquake behaviors along 406 the strike.

\section{$407 \quad 5.1$ Along-strike variation in material properties}


Active-source wide-angle refraction study across the foreshock zone (i.e. segment

409 1) (Roland et al., 2012) imaged a low-velocity fault zone extending through the entire 410 crust with Vp reduced by 10-20\%. Similarly, P-wave tomographic study using the 411 earthquake data also showed a low-velocity fault zone in segment 1 (Froment et al., 412 2014). Based on the gravity data analysis, the low velocity fault zone is not likely 413 caused by the widespread serpentinization, instead it is most likely that the segment 1 414 is highly fractured with enhanced fluid-filled porosity (1.5-8\%) (Roland et al., 2012). 415 Further support of a highly damaged fault zone is from the temporal Vs variation 416 during the foreshock swarm, one week preceding the main shock (Froment et al., 417 2014). Using the doublet analysis, Froment et al. (2014) found that the Vs of the 418 foreshock zone is reduced up to $-3 \%$ when the foreshocks occurred, followed by 419 partial recovery to $\sim-2 \%$ during the one-week foreshock swarm period and then 420 further reduced up to $\sim-7 \%$ immediately when the main shock occurred, followed by 421 partial recovery to $\sim-2 \%$.

422 Compared to previous Vp images, our new $\mathrm{Vp} / \mathrm{Vs}$ model shows more details 423 along the strike in segment 1 (Figs. 8 and 9). For zones A and C with anomalously 424 high Vp/Vs and low Vp and Vs values, it can be explained by enhanced fluid-filled porosity, which would cause Vs decreasing more than Vp (Kuster and Toksöz, 1974; 426 Takei, 2002). Different amplitudes in Vp/Vs anomalies in zones A and C (Fig. 8c) could be caused by different degrees in porosity and/or pore shape (e.g. aspect ratio) 428 (Kuster and Toksöz, 1974; Takei, 2002). In addition, if fluids existed, a small amount 429 of serpentine minerals probably could exist although it is not the main cause for the 430 low Vp, Vs and high Vp/Vs (Roland et al. 2012).

431 Additional evidence for the existence of fluids in segment 1 comes from the deep extension of the seismicity in segment 1 (Fig. 6c). Oceanic seismogenic depths are 433 generally shallower than the $600^{\circ} \mathrm{C}$ isotherm (Abercrombie and Ekstrom, 2001; 434 McKenzie et al., 2005), which corresponds to the depth of $\sim 4 \mathrm{~km}$ below the sea 435 bottom for a half-space cooling model, but can increase to $\sim 5-6 \mathrm{~km}$ (Fig. 6c) for a 436 thermal model including hydrothermal cooling (Roland et al., 2012). Although 437 earthquake depth extension in segment 1 is deeper than the prediction from this 
hydrothermal model (Fig. 6c), it could be explained if a certain degree of local fluid circulation is considered for a cooler model (McGuire et al., 2012; Roland et al.,

440 2012). Thus, enhanced earthquake depth extension supports the existence of fluids in 441 segment 1 which can increase the rheology transition depth from frictional to viscous 442 behaviors.

443 Although the explanation for deep seismicity at the bottom of zone B needs the 444 existence of fluids, however, zone B shows relatively low Vp/Vs (Fig. 9). Based on 445 the two-phase effective media calculation with different rock porosities, pore fluids, 446 and pore shapes (Kuster and Toksöz, 1974; Takei, 2002), a reduction of Vp/Vs needs 447 the aspect ratio of cracks to be large and/or a part of pore spaces being composed of 448 gas. Considering the high pressure in depth, the existence of pore gas is problematical 449 and thus large pore aspect ratio is more possible to explain the low Vp/Vs observed.

450 Compared to segment 1, segment 2 shows apparently different velocity structure 451 (Fig. 8). Froment et al. (2014) suggested the asperity segment 2 to be composed of 452 relatively intact gabbro and peridotite rocks inferred from higher Vp compared to 453 segments 1 and 3. Our model shows that overall segment 2 has higher Vp, higher Vs 454 compared to its adjacent segments (note that as mentioned in section 4.3.2, the lower 455 velocity in the deep area compared to segments 1 and 3 is just due to the crustal uplift 456 of segments 1 and 3 rather than being damaged). For the undamaged gabbro in the 457 middle and lower oceanic crust, its normal $\mathrm{Vp} / \mathrm{Vs}$ value is $\sim 1.8-1.85$ which has some 458 variations with different content of olivine in gabbro (Christensen, 1996). The Vp/Vs 459 value $(\sim 1.8)$ of segment 2 is relatively normal compared to that of the adjacent 460 segments. Thus, our new models also indicate the asperity segment 2 to be composed 461 of relatively intact rocks compared to segments 1 and 3.

462 Similar to zones $\mathrm{A}$ and $\mathrm{B}$, zones $\mathrm{D}$ and $\mathrm{E}$ in segment 3 show low $\mathrm{Vp}$, low Vs and 463 high Vp/Vs anomalies, implying high fluid-filled porosity within them. Same as 464 segment 1 , additional evidence for the existence of fluids in segment 3 comes from 465 the enhanced earthquake depths (Fig. 6c). Similar to segment 2, the zone in 466 seismogenic depth from $\mathrm{Z}=6$ to $8 \mathrm{~km}$ and $\mathrm{X}=-20$ to $-16 \mathrm{~km}$ (i.e. between zones $\mathrm{D}$ 
and $\mathrm{E}$ ) is associated with relatively normal $\mathrm{Vp}$, $\mathrm{Vs}$ and $\mathrm{Vp} / \mathrm{Vs}$, indicating relatively intact rocks there.

\subsection{Structural control on the generation and propagation of the main shock}

High-resolution relocations and velocity models reveal some relationships between structural variations and large earthquakes in the seismogenic depth of $\sim 6$ to $8 \mathrm{~km}$. Large earthquakes, including the 2008 M6 mainshock, occur quasiperiodically in segment 2 where we image a relatively intact fault zone. By contrast, the rupture barrier segment 1 to the east shows two large-scale, highly damaged zones at its eastern and western boundaries, and the segment 3 to the west, shows two small-scale, damaged zones. With weak pre-main shock seismicity (Fig. 7), the $\sim 8 \mathrm{~km}$-long segment 2 composing of relatively intact rocks could be relatively locked during the interseismic period to accumulate stress, which was released quasiperiodically by large M6 earthquakes associated with coseismic damage of the fault zone, as evidenced by the coseismic velocity decrease (Froment et al., 2014). In segment 3 where no M6 earthquake has been observed, however, another zone between D and E in the seismogenic depth of 6 to $8 \mathrm{~km}$ is also suggested to be relatively intact. Compared to the $\sim 8 \mathrm{~km}$-long segment 2 , small length ( $\sim 4 \mathrm{~km}$-long) or size of the intact seismogenic zone in segment 3 may be responsible for its inability of generating large earthquakes. Thus, we suggest that a relatively intact fault zone with sufficient scale is necessary for the stress build-up for large earthquakes.

Intense foreshocks in segment 1 one week before the main shock associated with some aseismic events within segment 1 could make the fault zone to be dilatant strengthening and increase the porosity of the damaged zones $\mathrm{A}$ and $\mathrm{C}$, as evidenced from the velocity decrease during the foreshock period (McGuire et al., 2012; Froment et al., 2014). The resulting dilatant strengthening and a small amount of serpentine minerals within zones $\mathrm{A}$ and $\mathrm{C}$ may be able to prevent the subsequent main shock slip passing through (Segall et al., 2010; Segall and Bradley, 2012; McGuire et al., 2012; Roland et al., 2012; Froment et al., 2014). Different to segment 1, intensive seismicity in segment 3 after the main shock could indicate that the mainshock 
rupture was likely able to pass through this segment, which may be due to relatively small length of zones D and E ( 2km-long) in the seismogenic depth of $\sim 6$ to $8 \mathrm{~km}$ compared to zones $\mathrm{A}$ and $\mathrm{C}$ ( $4 \mathrm{~km}-\mathrm{long})$ in segment 1 . Thus, we suggest that a damaged zone with sufficient scale would be necessary to stop the rupture propagation of large earthquakes.

Global observations inferred a low seismic coupling ( 15\%) on RTFs, i.e. most areas that are thermally predicted to be capable of generating large earthquakes (Abercrombie and Ekstrom, 2001) slip aseismically (Bird et al., 2002; Boettcher and Jordan, 2004). Considering the similar scaling relationship between Gofar TF and other RTFs (Boettcher and Jordan, 2004), our model suggests that the existence of fluid-filled, damaged zones with different scales is likely responsible for the deficit of seismic slip on global RTFs (Froment et al., 2014).

\subsection{Structural control on small earthquakes}

High-resolution relocations and velocity models reveal some relationships between structural variations and small earthquakes. Overall, small earthquakes along the strike are highly segmented into different clusters (Figs. 6b and 7), among which some horizontal, slip-parallel earthquake streaks can be clearly seen, e.g. the one around $X=-7 \mathrm{~km}$ shown in Fig 6b. Such spatial distribution of small earthquakes has been observed in continental strike-slip faults and suggested to be structural in origin (Rubin et al., 1999; Waldhauser et al., 1999, 2004; Schaff et al., 2002; Waldhauser and Ellsworth, 2002).

In segment 1, most background earthquakes and foreshocks tend to occur near the boundaries of the anomalous zones A, B, and C (Fig. 9), indicating that the nucleation and spatial distribution of small earthquakes in segment 1 is structurally controlled. Most foreshocks are concentrated into a very narrow region from $X=-0.5$ to $0.5 \mathrm{~km}$ between zones B and C (Fig. 9). Following the suggestion from McGuire et al. (2012) that the week-long foreshocks were likely to be triggered by a large aseismic creep event in the foreshock zone, we further suggest that if it existed, this aseismic event could be generated in zone B which has very weak seismicity in the whole year in 
depth of 6 to $9 \mathrm{~km}$. As a result, the stress perturbations from the aseismic event can be effectively transferred around zone $\mathrm{B}$, especially to the area between $\mathrm{B}$ and $\mathrm{C}$ to trigger most foreshocks there. But the triggering aseismic event is also possible to be in shallower depth at the same time as found in continental strike-slip faults (Lohman and McGuire, 2007; Wei et al., 2013). In addition, the deeper zone in depth of 9 to 10 $\mathrm{km}$ at the bottom of $\mathrm{B}$ experienced relatively active seismicity after the main shock compared to the zone in depth of 6 to $8 \mathrm{~km}$ above it but still much weaker than its pre-main shock level (Fig. 9). This deep zone with deep seismicity has relatively low $\mathrm{Vp} / \mathrm{Vs}$, implying different earthquake generation mechanism there compared to the shallow seismogenic zone in depth of $6 \sim 8 \mathrm{~km}$. In segment 2, two earthquake clusters around $X=-10 \mathrm{~km}$ after the main shock (Figs. 7 and 8) are separated, which may be related to the coseismic damage as evidenced by the coseismic velocity decrease observed in this segment (Froment et al., 2014). In segment 3, damaged zones D and E have weak seismicity within them but have some earthquake clusters surrounding them (Figs. 7 and 8). Thus, we suggest that structural variations along the strike control the nucleation and spatial distribution of small earthquakes.

Highly segmented seismicity seen from the spatial and temporal evolution of the year-long seismicity (Fig. 7) indicates even stronger structural variations along the strike than what we have imaged due to limited spatial resolutions of seismic tomography using seismic travel times employed in this study.

\section{Conclusions}

We have determined high-resolution earthquake locations and $\mathrm{Vp}$, Vs and $\mathrm{Vp} / \mathrm{Vs}$ models along the Gofar TF, East Pacific Rise, using a new consistency constrained DD tomography method. New earthquake locations and velocity models reveal detailed structural variations and their spatial correlation with earthquake behaviors along the strike. The M6 mainshock is associated with a $~ 8 \mathrm{~km}$-long segment with high $\mathrm{Vp}$, high $\mathrm{Vs}$ and relatively normal $\mathrm{Vp} / \mathrm{Vs}$ values, which is composed of relatively intact gabbro and peridotite rocks. It is stronger than neighboring segments 
556 and acts as the asperity for quasiperiodically occurring large earthquakes. The

557 neighboring segment to the east acts as the rupture barrier for the main shock, whose

558 boundaries are suggested to be associated with two fluid-filled, damaged zones with

559 low $\mathrm{Vp}$, low $\mathrm{Vs}$ and high $\mathrm{Vp} / \mathrm{Vs}$ at the low-crustal seismogenic depth. The

560 neighboring segment to the west cannot generate any large earthquake because of the

561 limited scale of the intact seismogenic zone and also cannot fully stop large

562 earthquake rupture propagation because of the limited scale of the damaged zones at

563 the seismogenic depth. Along the strike, small earthquakes prefer to occur within the

564 zones with relatively normal $\mathrm{Vp} / \mathrm{Vs}$ values or around the boundaries between high and

565 normal/low $\mathrm{Vp} / \mathrm{Vs}$ anomalies. Thus, strong structural variation in the material

566 properties along the strike as evidenced by earthquake locations and velocity models

567 controls the behaviors of large and small earthquakes and is likely responsible for the

568 deficit of seismic slip on global RTFs. The application of high-resolution imaging to

569 the Gofar TF shows that by imaging the along-strike variations of velocity models,

570 especially $\mathrm{Vp} / \mathrm{Vs}$, it is very helpful for better understanding earthquake behavior and

571 oceanic fault mechanical behavior. This kind of work would be interesting in a global

572 perspective for better understanding earthquake behaviors based on fault structural

573 characteristics. 


\section{Acknowledges}

We thank Dr. Jeff McGuire for very helpful discussion on the result and interpretation. All the waveform data used was acquired by WHOI and has been archived at the IRIS Data Center.

\section{References}

Bird, P., Kagan, Y. Y., \& Jackson, D. D., 2002. Plate tectonics and earthquake potential of spreading ridges and oceanic transform faults (pp. 203-218). American Geophysical Union.

Boettcher, M. S., Jordan, T. H., 2004. Earthquake scaling relations for mid-ocean ridge transform faults. Journal of Geophysical Research: Solid Earth, 109(B12).

Detrick, R. S., White, R. S., \& Purdy, G. M., 1993. Crustal structure of North Atlantic fracture zones. Reviews of Geophysics, 31(4), 439-458.

Du, W. X., Thurber, C. H., \& Eberhart-Phillips, D., 2004. Earthquake relocation using cross-correlation time delay estimates verified with the bispectrum method. Bulletin of the Seismological Society of America, 94(3), 856-866.

Froment, B., McGuire, J. J., Hilst, R. D., Gouédard, P., Roland, E. C., Zhang, H., \& Collins, J. A., 2014. Imaging along - strike variations in mechanical properties of the Gofar transform fault, East Pacific Rise. Journal of Geophysical Research: Solid Earth, 119(9), 7175-7194.

Gouédard, P., Seher, T., McGuire, J. J., Collins, J. A., \& van der Hilst, R. D., 2014. Correction of ocean - bottom seismometer instrumental clock errors using ambient seismic noise. Bulletin of the Seismological Society of America, 104(3), 1276-1288.

Guo, H., and Zhang, H., 2017. Development of double-pair double difference earthquake location algorithm for improving earthquake locations, Geophys. J. Int., 208(1), 333-348.

Harris, R. A., 2017. Large earthquakes and creeping faults. Reviews of Geophysics, 55(1), 169-198.

Ide, S., Beroza, G. C., Shelly, D. R., \& Uchide, T., 2007. A scaling law for slow earthquakes. Nature, 447(7140), 76-79.

Kuster, G. T., \& Toksöz, M. N., 1974. Velocity and attenuation of seismic waves in two-phase media: Part I. Theoretical formulations. Geophysics, 39(5), 587-606.

Lohman, R. B., \& McGuire, J. J., 2007. Earthquake swarms driven by aseismic creep in the Salton Trough, California. Journal of Geophysical Research: Solid Earth, 112(B4).

McGuire, J. J., 2008. Seismic cycles and earthquake predictability on East Pacific Rise transform faults. Bulletin of the Seismological Society of America, 98(3), 1067-1084.

McGuire, J.J., Collins, J.A., Gouédard, P., Roland, E., Lizarralde, D., Boettcher, M.S., Behn, M.D. and Van Der Hilst, R.D., 2012. Variations in earthquake rupture properties along the Gofar transform fault, East Pacific Rise. Nature Geoscience, 5(5), p.336. 
McKenzie, D., Jackson, J., \& Priestley, K., 2005. Thermal structure of oceanic and continental lithosphere. Earth and Planetary Science Letters, 233(3), 337-349.

Peng, Z., \& Gomberg, J., 2010. An integrated perspective of the continuum between earthquakes and slow-slip phenomena. Nature Geoscience, 3(9), 599-607.

Pickle, R. C., Forsyth, D. W., Harmon, N., Nagle, A. N., \& Saal, A., 2009. Thermo-mechanical control of axial topography of intra-transform spreading centers. Earth and Planetary Science Letters, 284(3), 343-351.

Roland, E., Lizarralde, D., McGuire, J. J., \& Collins, J. A., 2012. Seismic velocity constraints on the material properties that control earthquake behavior at the Quebrada - Discovery - Gofar transform faults, East Pacific Rise. Journal of Geophysical Research: Solid Earth (1978-2012), 117(B11).

Rubin, A.M., Gillard, D. \& Got, J.L., 1999. Streaks of microearthquakes along creeping faults, Nature, 400(6745), 635-641.

Schaff, D.P., Bokelmann, G.H., Beroza, G.C., Waldhauser, F. \& Ellsworth, W.L., 2002. High-resolution image of Calaveras Fault seismicity, J. geophys. Res., 107(B9), 2186, doi:10.1029/2001JB000633.

Segall, P., Rubin, A. M., Bradley, A. M., \& Rice, J. R., 2010. Dilatant strengthening as a mechanism for slow slip events. Journal of Geophysical Research: Solid Earth (1978-2012), 115(B12).

Segall, P., \& Bradley, A. M., 2012. The role of thermal pressurization and dilatancy in controlling the rate of fault slip. Journal of Applied Mechanics,79(3), 031013.

Takei, Y. (2002). Effect of pore geometry on Vp/Vs: From equilibrium geometry to crack. Journal of Geophysical Research: Solid Earth, 107(B2).

Waldhauser, F., \& Ellsworth, W. L., 2000. A double-difference earthquake location algorithm: Method and application to the northern Hayward fault, California. Bulletin of the Seismological Society of America, 90(6), 1353-1368.

Waldhauser, F. \& Ellsworth, W.L., 2002. Fault structure and mechanics of the Hayward fault, California, from double-difference earthquake locations, J. geophys. Res., 107(B3), doi:10.1029/2000JB000084.

Waldhauser, F., Ellsworth, W.L. \& Cole, A., 1999. Slip-parallel seismic lineations on the northern Hayward fault, California, Geophys. Res. Lett., 26(23), 3525-3528.

Waldhauser, F., Ellsworth, W.L., Schaff, D.P. \& Cole, A., 2004. Streaks, multiplets, and holes: High-resolution spatio-temporal behavior of Parkfield seismicity, Geophys. Res. Lett., 31(18), doi:10.1029/2004GL020649.

Wei, M., Kaneko, Y., Liu, Y., McGuire, J. J., 2013. Episodic fault creep events in California controlled by shallow frictional heterogeneity. Nature geoscience. Jul;6(7):566.

Yao, H., Gouedard, P., Collins, J. A., McGuire, J. J., \& van der Hilst, R. D., 2011. Structure of young East Pacific Rise lithosphere from ambient noise correlation analysis of fundamental-and higher-mode Scholte-Rayleigh waves. Comptes Rendus Geoscience, 343(8), 571-583.

Zhang, H., \& Thurber, C. H., 2003. Double-difference tomography: The method and its application to the Hayward fault, California. Bulletin of the Seismological Society of America, 93(5), 1875-1889. 
Zhang, H., Thurber, C., \& Bedrosian, P., 2009. Joint inversion for vp, vs, and vp/vs at 663 SAFOD, Parkfield, California. Geochemistry, Geophysics, Geosystems, 10(11).

664 Zhang, H., Thurber, C., \& Rowe, C., 2003. Automatic P-wave arrival detection and picking with multiscale wavelet analysis for single-component

666 recordings. Bulletin of the Seismological Society of America, 93(5), 1904-1912.

667 Zhao, D., \& Hasegawa, A., 1993. P wave tomographic imaging of the crust and upper

668 mantle beneath the Japan Islands. Journal of Geophysical Research: Solid $669 \quad$ Earth, 98(B3), 4333-4353.

670 

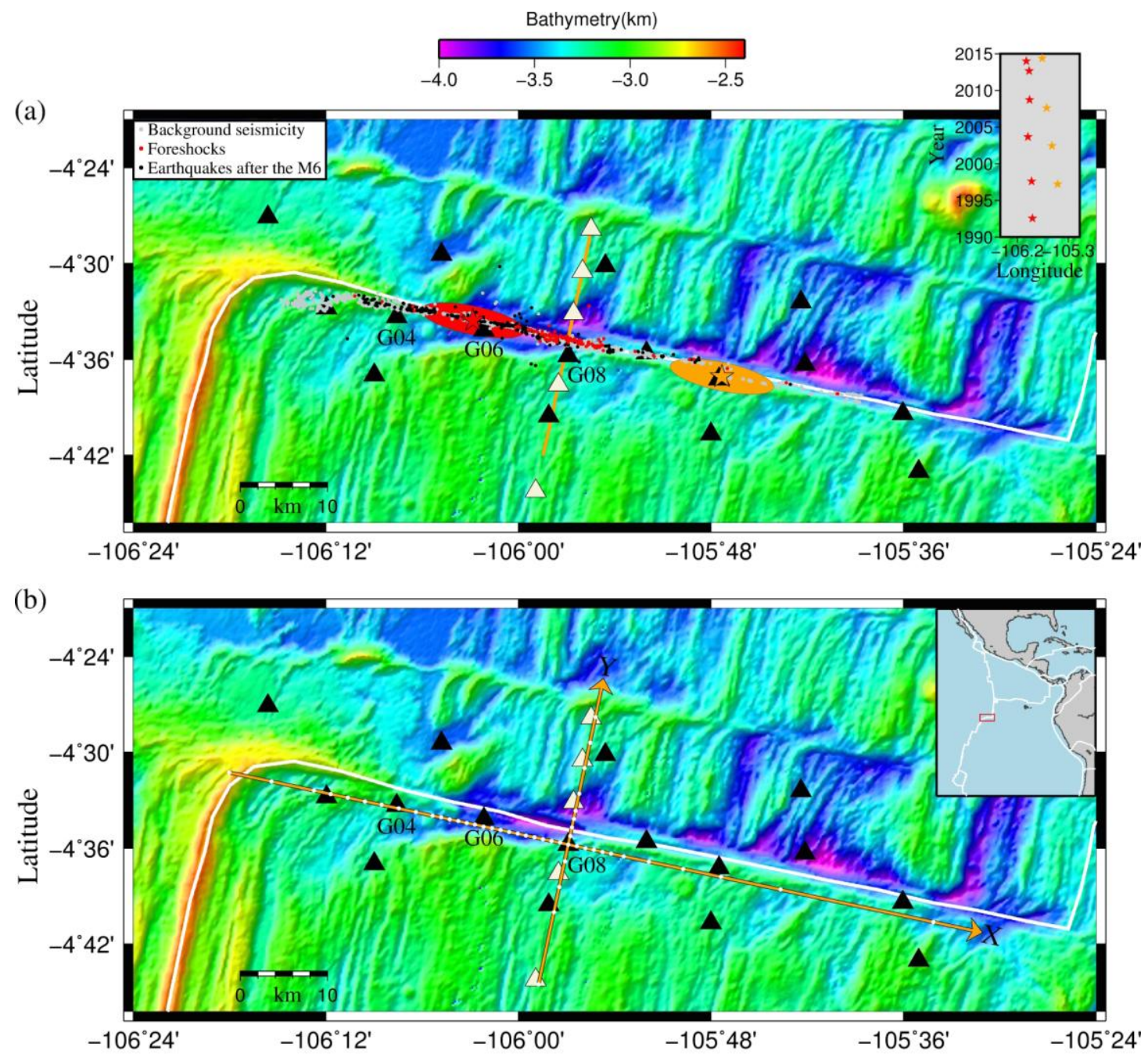

Longitude

672 Figure 1. (a) Distribution of earthquakes and stations (triangles) around the Gofar

673 transform fault. Black triangles represent the OBS sites deployed for the one-year

674 passive-source experiment in 2008, among which stations G04, G06 and G08 are

675 labeled. Beige triangles represent the OBS sites deployed for the active-source

676 experiment. Orange dots forming a line crossing the fault represent the active-source

677 air-gun shots. Gray, red and black dots represent the relocations of background

678 earthquakes, foreshocks and the earthquakes after the main shock with small location

679 uncertainties, respectively. Note that compared to Fig. 5a, the relocations after the

680 main shock shown Fig. 1a are within 20 days after the main shock. Red and orange

681 ellipses represent $\sim 10 \mathrm{~km}$-length asperity zones centered on the $2008 \mathrm{M}_{\mathrm{w}} 6.0$ (red star)

682 and $2007 \mathrm{M}_{\mathrm{w}} 6.2$ (orange star) main shocks, respectively. The locations of these two

683 M6 main shocks are determined by McGuire et al. (2012). As shown in the temporal 
684 evolution plot in the upper-right, these two asperities generate large earthquakes (i.e. 685 red and orange stars in the upper-right plot) event $\sim 5-6$ years (note that the locations 686 of these large earthquakes are from Global GCMT catalog, which has relatively large 687 location uncertainties. See McGuire (2008) for details on how to define the 688 overlapping rupture patches for these large earthquakes). (b) Cartesian coordinate 689 system and grid setting for the inversion. The $\mathrm{X}$ - and Y-axes of the Cartesian 690 coordinate system are represented by orange lines, with arrows pointing to the 691 positive directions and the coordinate center at G08. The white dots on the coordinate 692 axis represent the grid nodes used for the inversion in $\mathrm{X}$ and $\mathrm{Y}$ directions. The inset 693 map in the upper-right corner shows the geographic location of the study region. 

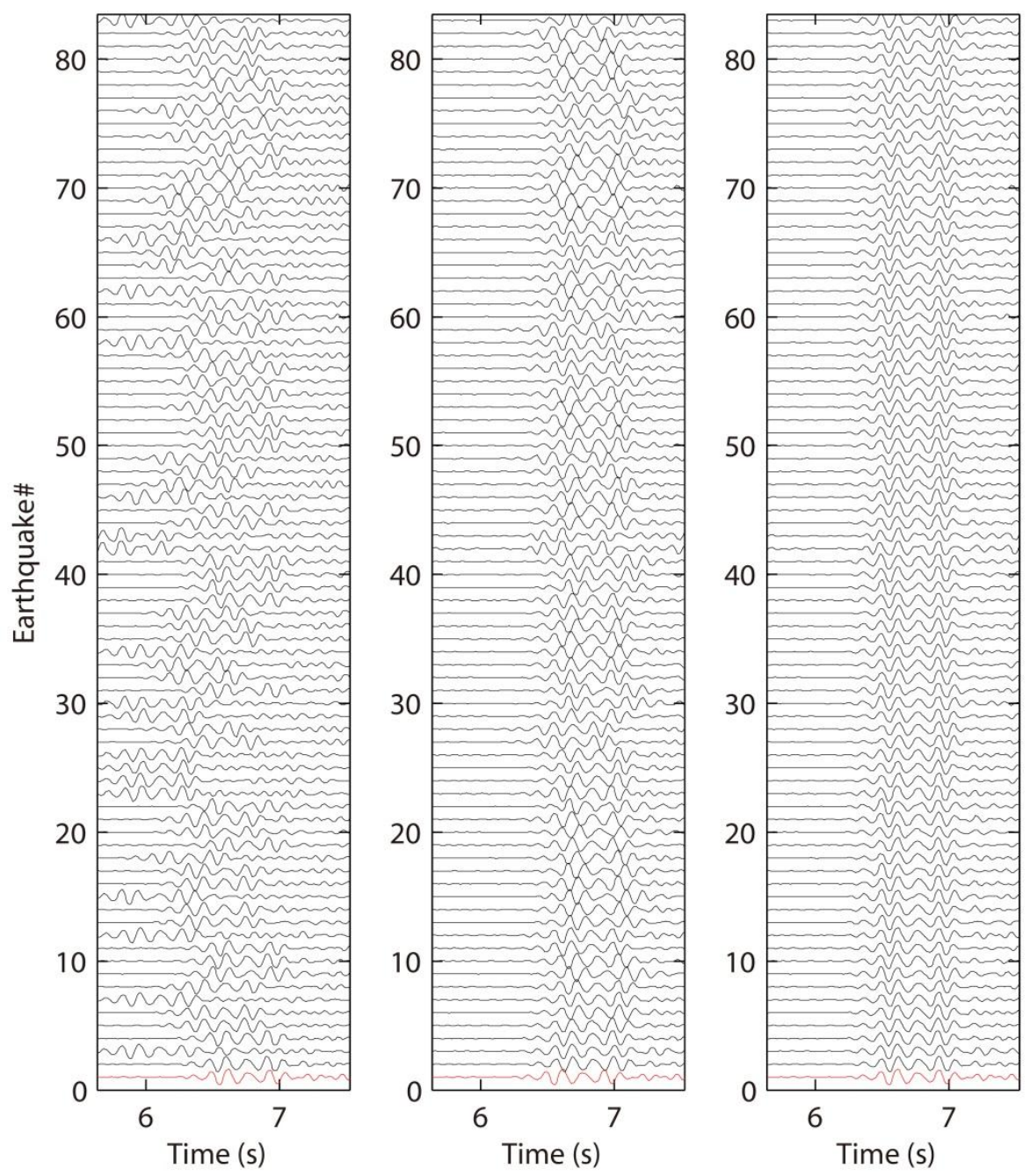

Figure 2. Comparison of waveform alignment for 83 nearby earthquakes recorded at

697 station G08. Black waveforms of 82 events are aligned to the waveform of a reference 698 event (the red one in the bottom) based on different sets of S-wave arrival times, 699 including (Left) catalog arrival times, (Middle) newly picked arrival times using the 700 arrival picking procedure introduced in Section 2.1 and (Right) arrival times 701 converted from WCC differential arrival times. WCC converted arrival times on black 702 waveforms are transformed from their respective WCC differential arrival times 703 relative to the reference waveform. Waveforms are filtered between 5 and $12 \mathrm{~Hz}$. 


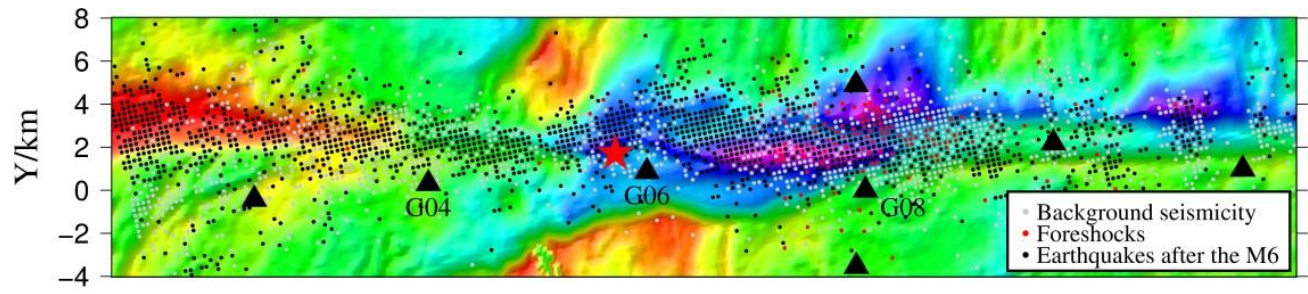

(a)

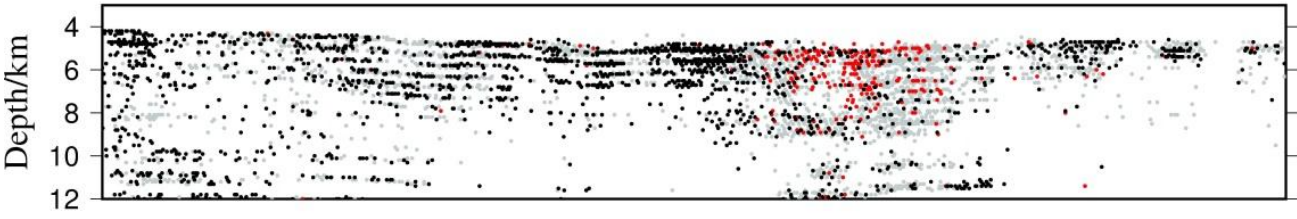

(b)

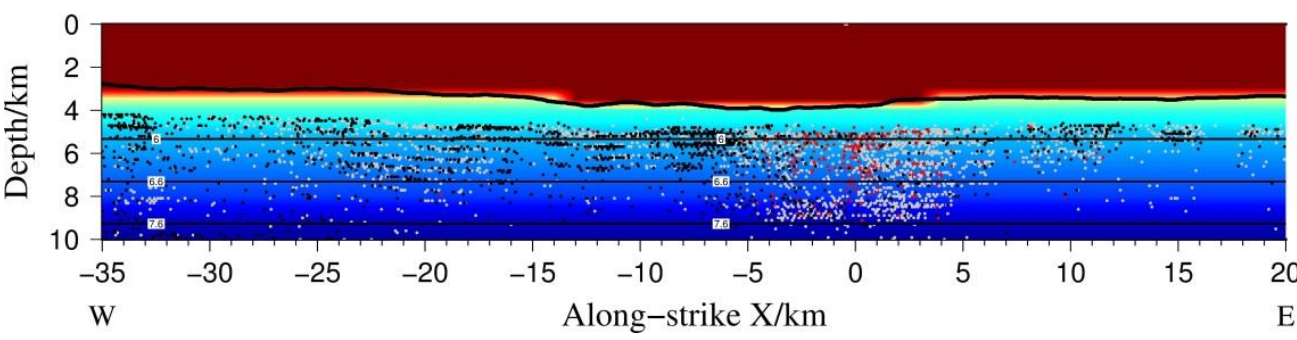

(c)

Figure 3. Distribution of catalog earthquake locations in map view (a) and

707 along-strike vertical cross section (b) as well as the initial velocity model along the

708 fault strike (c). Gray, red and black dots represent background earthquakes,

709 foreshocks and earthquakes after the main shock, respectively. In (c), bold black line

710 represents the local bathymetry. The dark red region associated with $\mathrm{Vp}$ of $1.5 \mathrm{~km} / \mathrm{s}$

711 above the seafloor represents the seawater. Velocity is contoured at 6.0, 6.6 and 7.6

$712 \mathrm{~km} / \mathrm{s}$, respectively. 

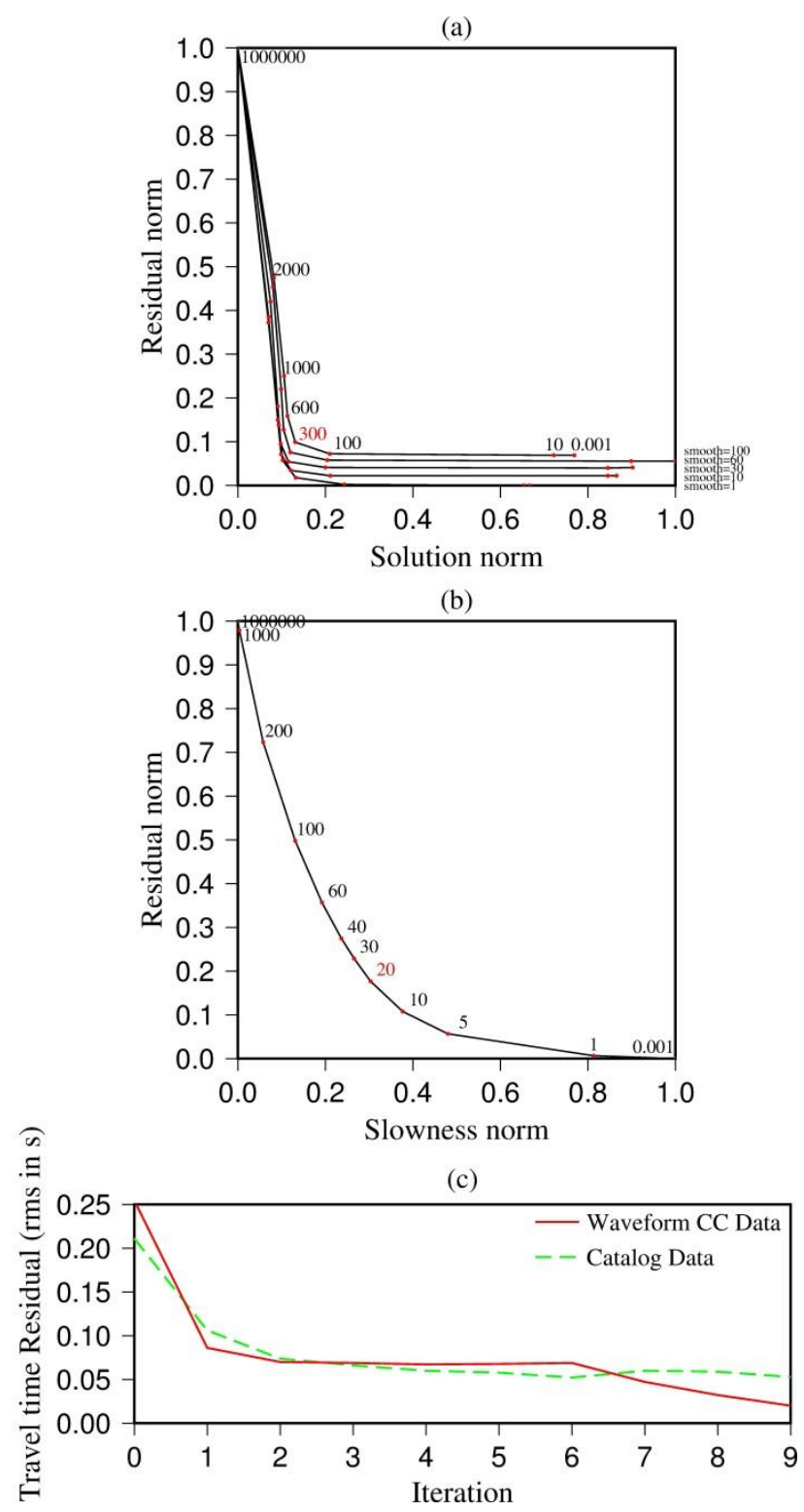

714 Figure 4. Trade-off analysis for selection of optimal damping and smoothing 715 parameters as well as the evolution of travel time residuals with the iterations. (a)

716 Trade-off analysis between the normalized solution norm and data residual norm from 717 inversions with a set of smoothing and damping parameters to select optimal damping 718 parameter. Different curves represent disparate smoothing parameters of 1, 10, 30, 60 719 and 100, with 100 at the top and 1 at the bottom. Red dots associated with same 720 smoothing parameter on each curve represent different damping parameters. Both 721 location and slowness parameters are included for the calculation of the solution norm 722 because the damping parameter is applied to constrain the slowness and earthquake 723 location at the same time during the joint inversion. The optimal damping parameter 
724 is selected around 300. (b) Trade-off analysis between normalized slowness norm and

725 data residual norm for a set of smoothing parameters using the optimal damping 726 parameter of 300 . Because the smoothing parameter is applied to constrain the 727 slowness, only the norm of slowness is used for the analysis of optimal smoothing 728 parameter. The optimal smoothing parameter is selected around 20. (c) Evolution of 729 the root-mean-square travel time residuals for the catalog times and WCC differential 730 times as a function of the iteration number in the inversion. The WCC data is 731 weighted more than the catalog data from iteration 7, resulting in a stair-step pattern 732 at iteration 7. 
(a) $V p$

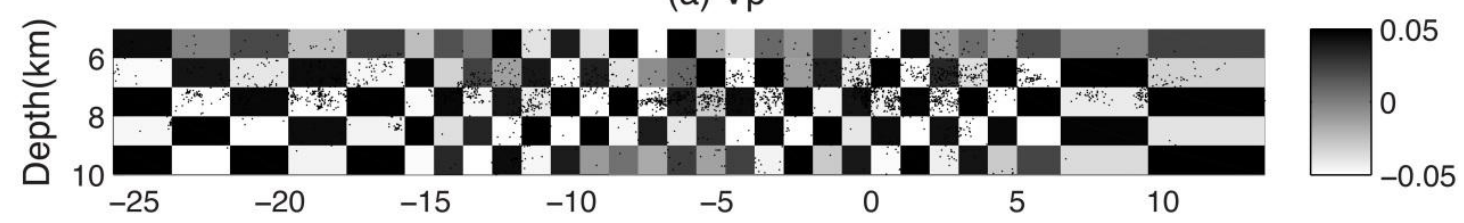

(b) Vs

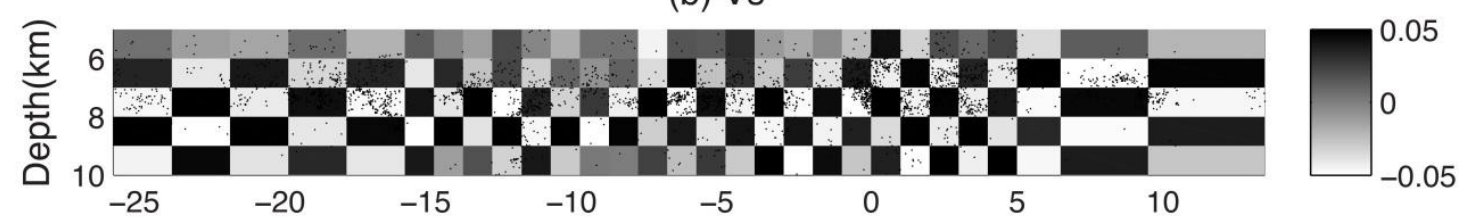

(c) $\mathrm{Vp} / \mathrm{Vs}$ (with consistency constraint)

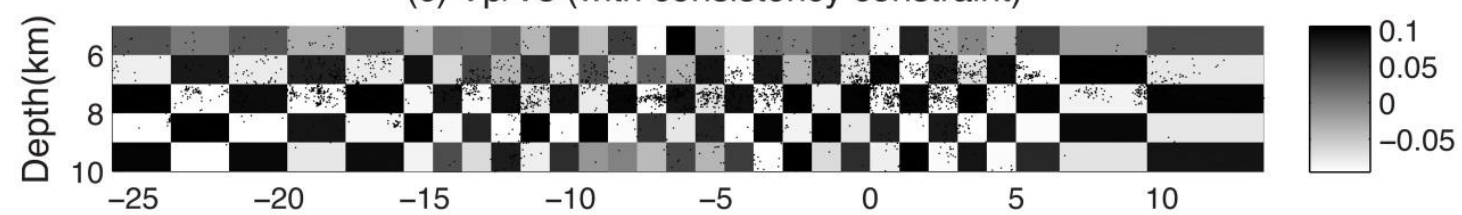

(d) $\mathrm{Vp} / \mathrm{Vs}$ (without consistency constraint)

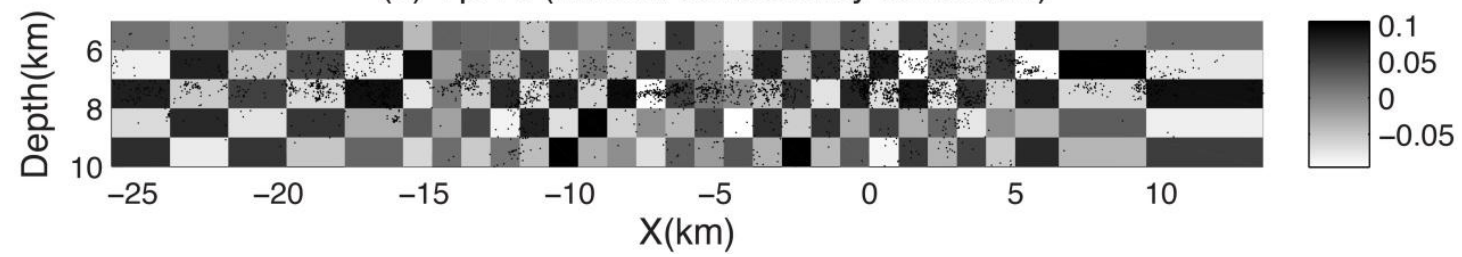

735 Figure 5. Vertical along-strike cross section at $\mathrm{Y}=2 \mathrm{~km}$ of the recovered

736 checkerboard patterns for the (a) Vp, (b) Vs, and (c) Vp/Vs model from the inversion

737 with the consistency constraint as well as (d) the recovered $\mathrm{Vp} / \mathrm{Vs}$ checkerboard

738 model from the inversion without the consistency constraint. Dots represent 739 earthquake locations. 


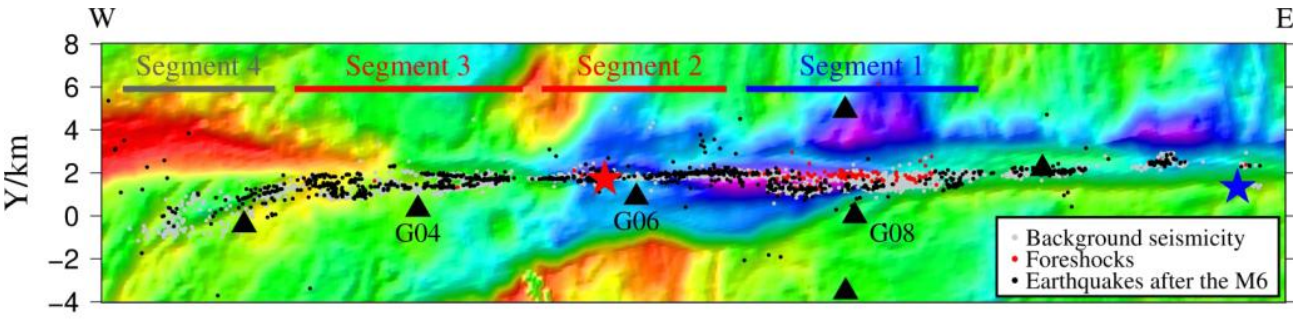

(a)

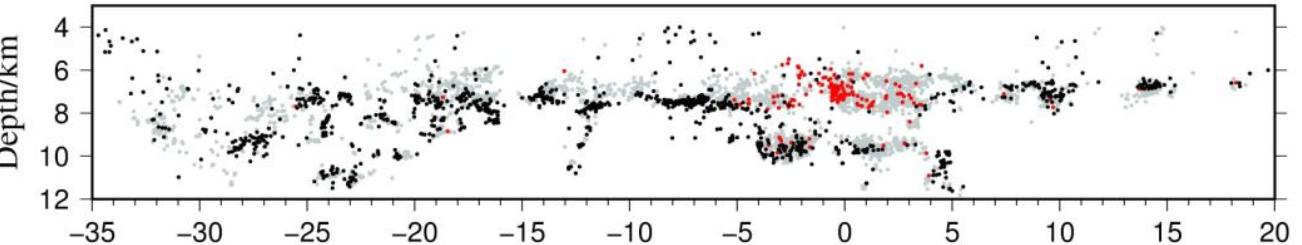

(b)

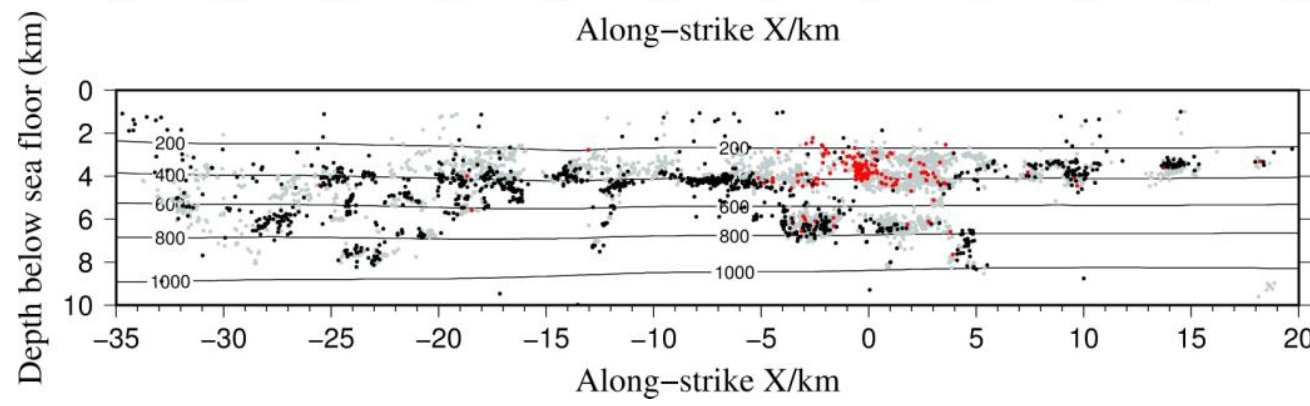

(c)

Figure 6. Distribution of earthquake relocations in the horizontal plane (a) and

743 along-strike vertical cross section (b and c). Only earthquakes with location

744 uncertainties less than $0.2 \mathrm{~km}$ in the $\mathrm{X}$ and $\mathrm{Y}$ directions and $0.3 \mathrm{~km}$ in the $\mathrm{Z}$ direction

745 are shown. In (b), earthquake depths are relative to the sea level. In (c), earthquake

746 depths are relative to the sea floor, which also takes the variation of topography into

747 account. The isotherms (labeled in degrees) of the thermal model from Roland et al.

748 (2012) are shown in (c). Segments 1-3 are the same as Froment et al. (2014) based on

749 the along-strike variation of material properties and segment 4 represents the

750 December swarm zone. 


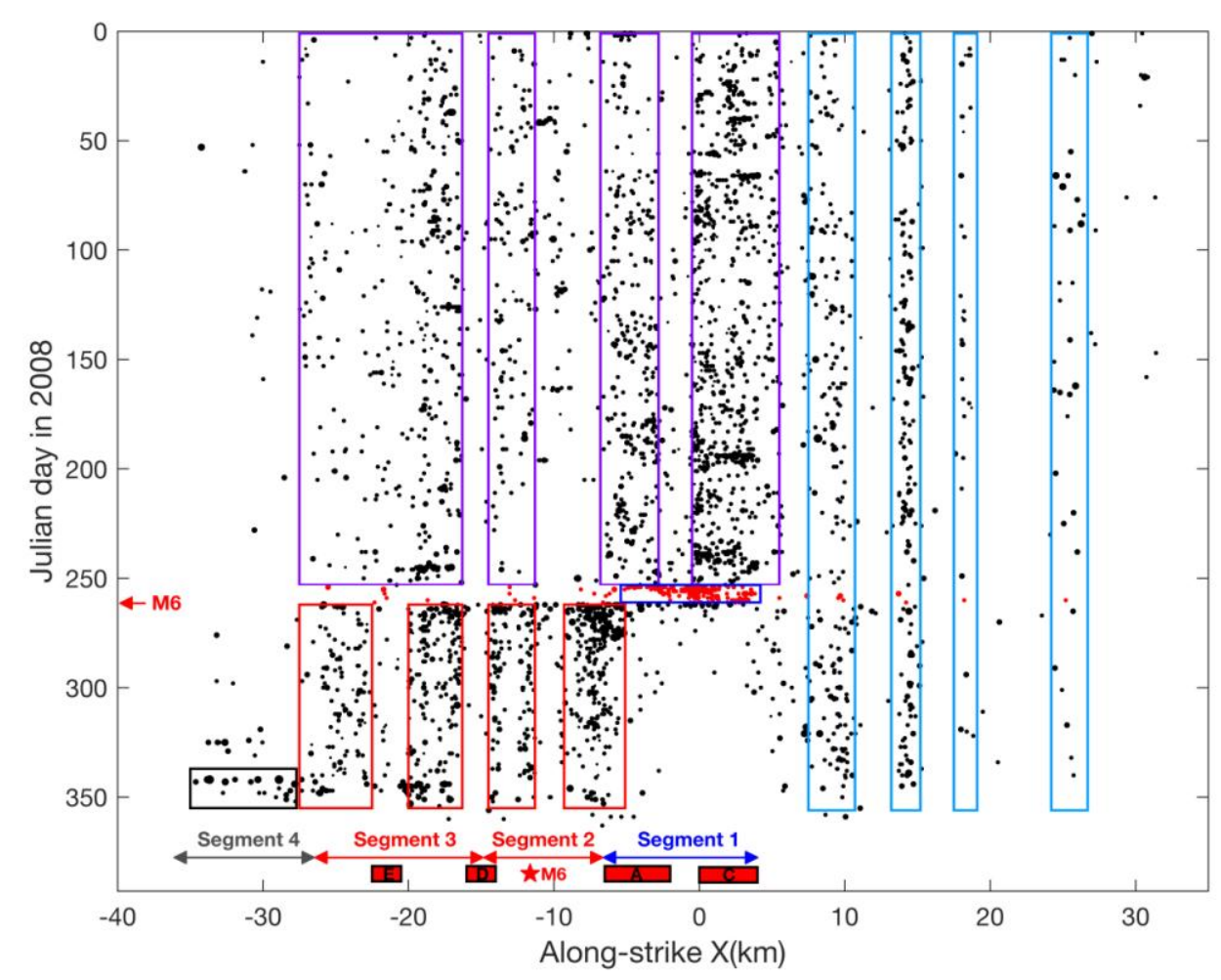

753 Figure 7. Temporal and spatial (along-strike) evolution of the year-long seismicity 754 (dots) between $\mathrm{Z}=6$ and $8 \mathrm{~km}$. Red dots represent earthquakes during the foreshock 755 period. Dot sizes are slightly adjusted based on their earthquake magnitudes. The 7562008 M6 earthquake is marked by the red star and red arrow in the horizontal and 757 vertical axes, respectively. Colored open rectangles are used to define earthquake 758 segmentations in space and time. Red solid rectangles indicate high $\mathrm{Vp} / \mathrm{Vs}$ anomaly 759 zones shown in Fig. 8 and their along-strike lengths represent the lengths of these anomalies in the seismogenic depth of $Z=6$ to $8 \mathrm{~km}$. Segments 1-4 are marked. 


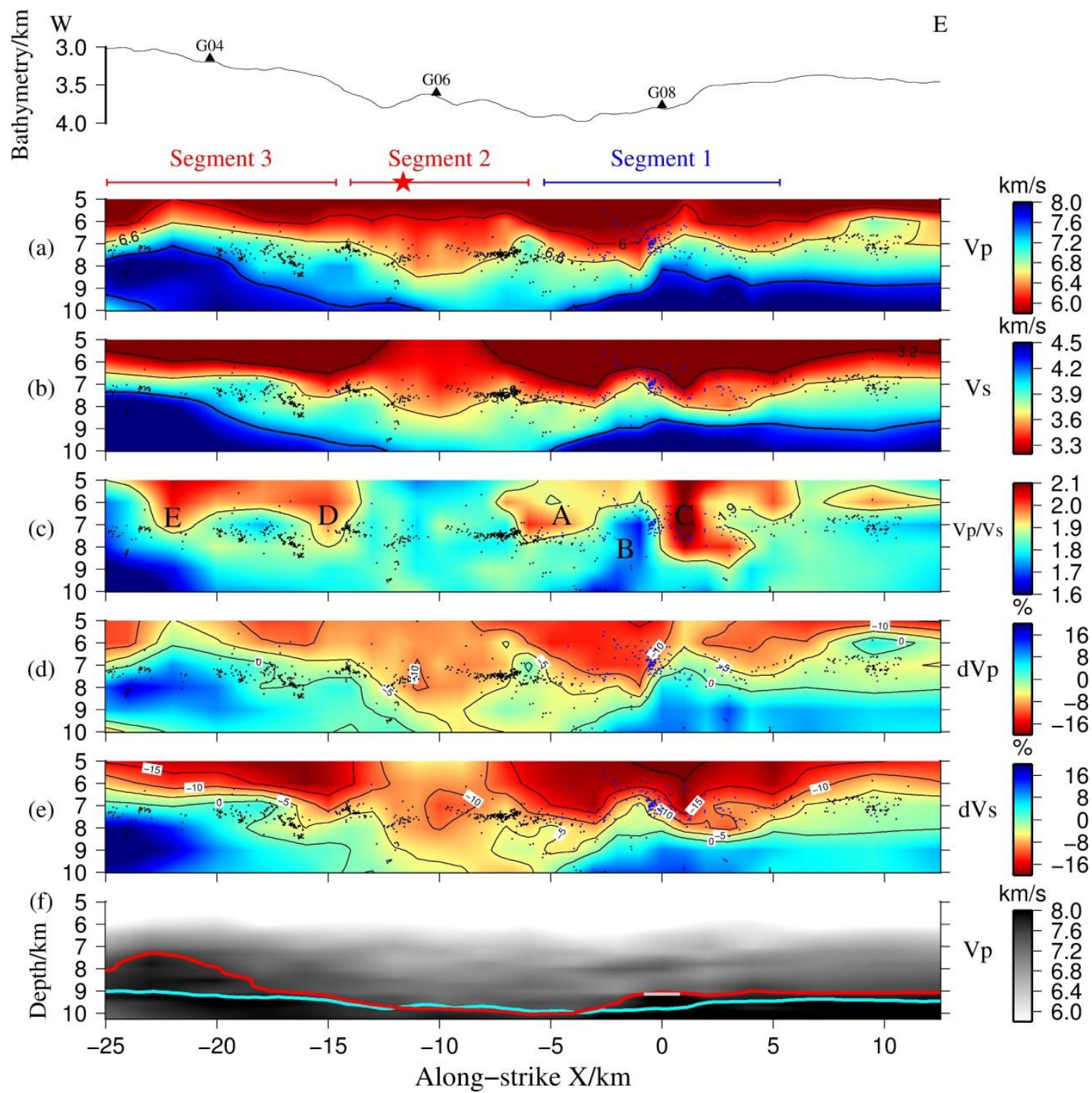

Along-strike $\mathrm{X} / \mathrm{km}$

762 Figure 8. Along-fault ( $X=-25$ to $12.5 \mathrm{~km}$ ) vertical cross sections of the (a) $\mathrm{Vp}$, (b)

763 Vs , (c) Vp/Vs, (d) $d V p$ and (e) dVs models as well as (f) Moho variations at $\mathrm{Y}=2$

$764 \mathrm{~km}$. In the top, the local bathymetry is shown and the stations G04, G06 and G08 are

765 also labeled. Vp model is contoured at $6.0,6.6$ and $7.6 \mathrm{~km} / \mathrm{s}$. Vs model is contoured at $7663.2,3.66$ and $4.2 \mathrm{~km} / \mathrm{s}$. Vp/Vs model is contoured at 1.9. Both $\mathrm{dVp}$ and $\mathrm{dVs}(\%)$ are 767 contoured at $-20,-15,-10,-5,0,5,10,15$ and 20 . Red star represents the 2008 main 768 shock (McGuire et al., 2012). Foreshocks and earthquakes after the main shock from $769 \mathrm{Y}=1.5$ to $2.5 \mathrm{~km}$ are represented by blue and black dots, respectively. In (f), Moho 770 discontinuity (red curve) is inferred from the $7.6 \mathrm{~km} / \mathrm{s}$ contour of the $\mathrm{Vp}$ model 771 resulted from a separate inversion with denser grid nodes in depth and coarser grid 772 nodes in the horizontal directions. The cyan curve represents the normal Moho 773 discontinuity by assuming the crustal thickness of $6 \mathrm{~km}$. The grey line at $X=0 \mathrm{~km}$ 
774 represents the Moho discontinuity estimated by Roland et al. (2012) from a 775 wide-angle refraction study.

776 

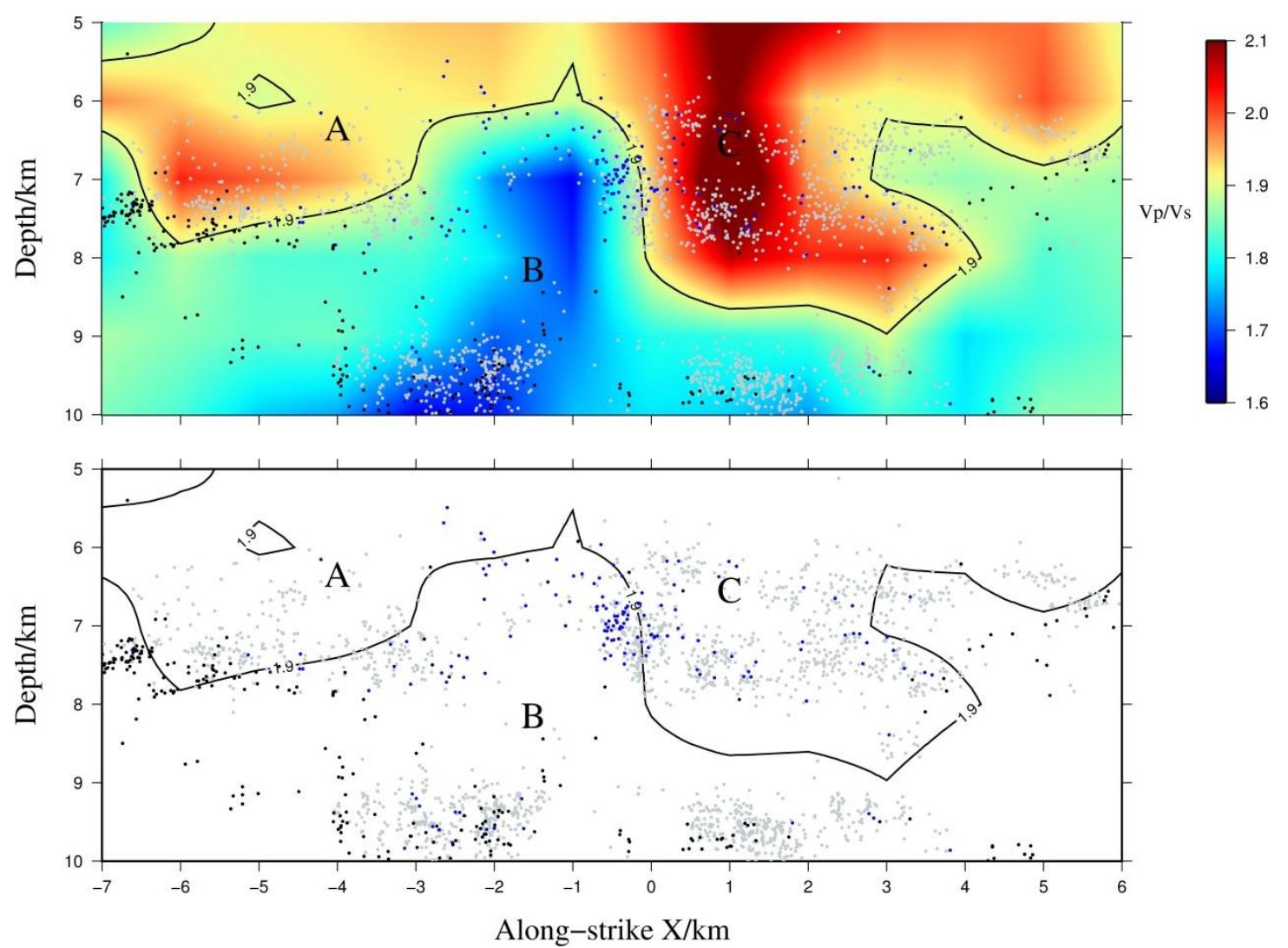

Figure 9. Zoom-in view of the vertical along-strike cross section at $\mathrm{Y}=2 \mathrm{~km}$ of $\mathrm{Vp} / \mathrm{Vs}$ anomalies and earthquakes from $\mathrm{X}=-7$ to $6 \mathrm{~km}$. In the bottom figure, only the 780 contour of $\mathrm{Vp} / \mathrm{Vs}=1.9$ is shown. Background earthquakes, foreshocks and 781 earthquakes after the main shock from $\mathrm{Y}=1$ to $2.5 \mathrm{~km}$ are shown as grey, blue and 782 black dots, respectively. Note that compared to Fig. 8c, deep earthquakes which are 783 located between $\mathrm{Y}=1$ and $1.5 \mathrm{~km}$ are also included. 